\title{
Induction of Puberty in a Patient with Constitutional Delayed Puberty
}

Tomoaki Sano, Kenji Ohyama, Yoshiko Nakagomi, Masanori Ohta, Toshitugu Yamori, Kazumasa Sato, Shin Amemiya and Shinpei Nakazawa

Department of Pediatrics, Yamanashi Medical University, Yamanashi, Japan

Key words: puberty, GnRH, testosterone, hCG, hypogonadism

\section{Introduction}

Constitutional delayed puberty (absence of pubertal modifications after 14-15 years of age) due to a transitory deficit of GnRH secretion often poses a difficult problem of differential diagnosis from permanent $\mathrm{GnRH}$ deficit, which can be identified only after 18 years of age in idiopathic hypogonadotropic hypogonadism. In the case of constitutional delayed puberty, treatment is not indicated for somatic reasons, although severe psychosomatic disturbances may make it necessary in many cases (1). Gonadotropins, GnRH, GRH, GH or sex steroids have been used in the therapy of constitutional delayed puberty (1). These methods aim to increase height velocity and promote sexual maturation.

We present here a case of constitutional delayed puberty. He was treated with pulsatile GnRH infusion and testosterone, and the effects on sexual development of both treatments are compared.

Correspondence: Dr. Tomoaki Sano, Department of Pediatrics, Yamanashi Medical University, 1110, Shimokato, Tamaho-cho, Nakakoma-gun, Yamanashi 409-38 Japan

\section{Case Report}

A 14 5/12-year-old boy (13 y of bone age) was referred to our hospital because of micropenis. He felt an inferiority complex about his lack of secondary sexual development. His height velocity had decreased for 4 years before the first visit $(4 \mathrm{~cm} / \mathrm{y})$, as shown in Fig 1. At the first visit he was $150 \mathrm{~cm}(-1.9 \mathrm{SD})$ tall and weighed $60 \mathrm{~kg}$ (obesity index: $+49 \%$ ). Pubertal development was at Tanner stage 1 (right testis $3 \mathrm{~mL}$, left testis $1 \mathrm{~mL}$, wandering; penile length $2 \mathrm{~cm}$ ). He had no anosmia and brain MRI showed no abnormal mass. Basal serum LH and FSH were 1.3 and $2.8 \mathrm{mIU} / \mathrm{mL}$ and did not change during nocturnal sleep. Peak LH and FSH after GnRH loading were 10.6 and $6.7 \mathrm{mIU} / \mathrm{mL}$ (early pubertal responses), respectively. Basal and peak serum testosterone ( $T$ ) levels after human chorionic gonadotropin loading (4,000 units im daily for 3 days) were 14 and $127 \mathrm{ng} / \mathrm{dL}$ (low response), respectively. Serum IGF-I level was $88 \mathrm{ng} / \mathrm{mL}$. Testicular biopsy revealed normal prepubertal tubular and interstitial compartments. We tentatively diagnosed him as constitutional delayed puberty but could not neglect the possibility of hypothalamic hypogonadism. 


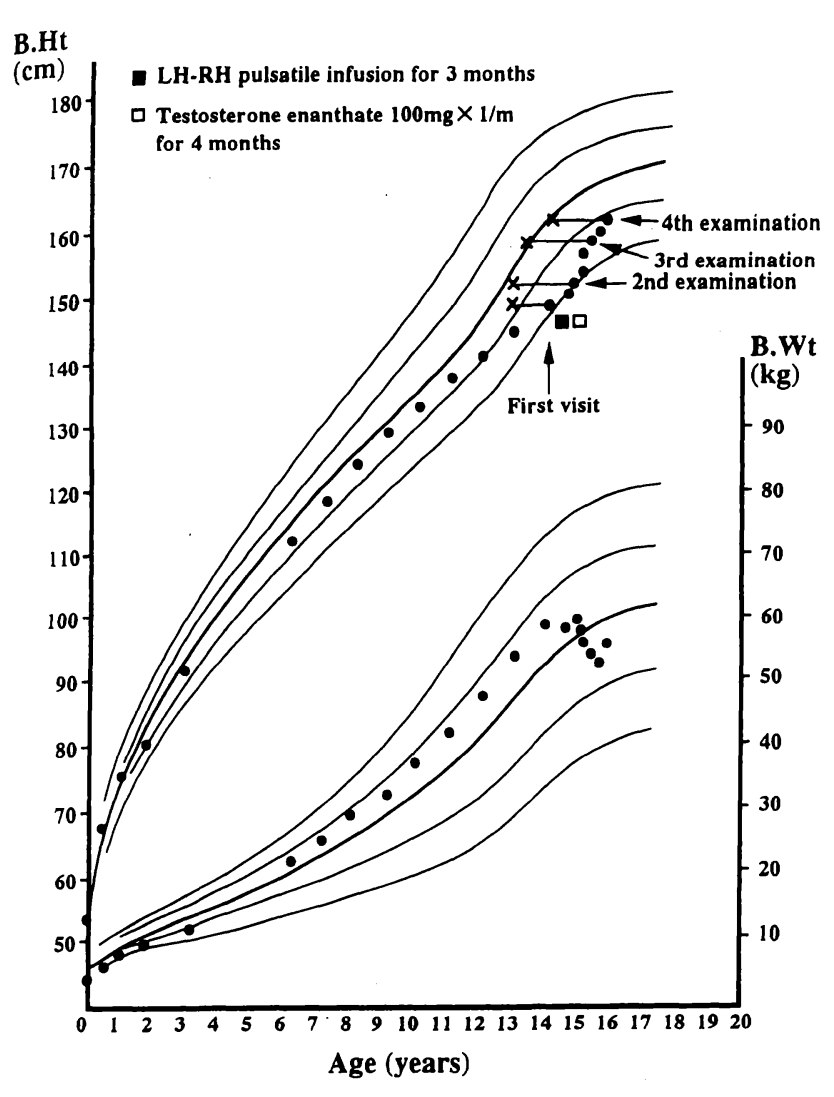

Fig. 1 Growth curve and clinical course in a patient with delayed adolescence

First, we treated him with pulsatile subcutaneous injections of $\mathrm{GnRH}$ for 3 months ( $20 \mu \mathrm{g}$ $\times 8$ daily every $90 \mathrm{~min}$ from 10:00 pm to 8:00 am). After this treatment, serum LH and FSH responses to the GnRH test decreased but the serum $\mathrm{T}$ level did not change (Table 1 ). Two months after the discontinuation of pulsatile $\mathrm{GnRH}$, we treated him with im injections of $\mathrm{T}$ ester for 4 months (100 mg/month). Two months later, the left testis had completely descended, bilateral testicular size had enlarged $(4 \mathrm{~mL})$ and height velocity increased $(13.2 \mathrm{~cm} / \mathrm{y})$. Five months after the discontinuation of $\mathrm{T}$ administration, testicular volume had continued to enlarge ( $8 \mathrm{~mL}$ each), pubic hair had appeared and serum $\mathrm{T}$ value increased to
Table 1 Endocrinological data

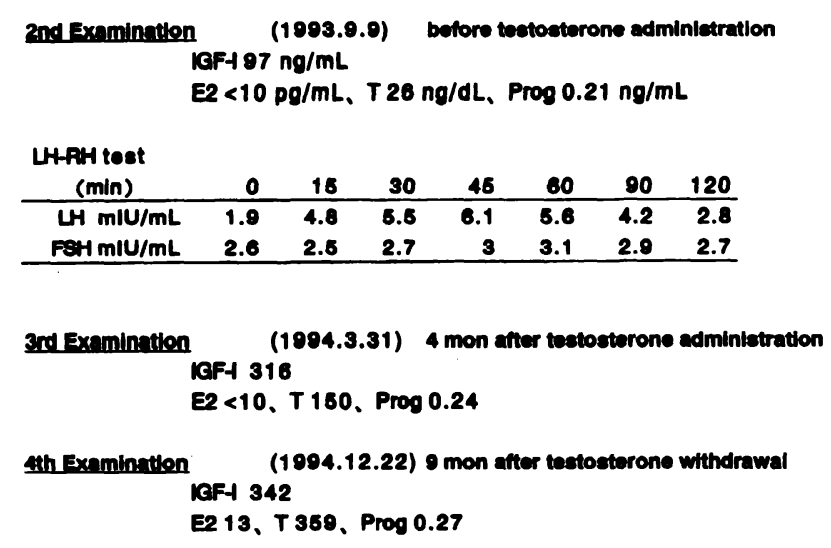

$333 \mathrm{ng} / \mathrm{dL}$.

\section{Disccusion}

In this case, the definite diagnosis was constitutional delayed puberty. Secondary sexual characteristics, including testicular enlargement, appeared 2 months after $\mathrm{T}$ administration. On the other hand, in the preceding three months of GnRH treatment, responses of serum $\mathrm{LH}$ and FSH to LHRH decreased compared with those before the treatment and the serum testosterone level did not increase. Pulsatile GnRH administration is the most nearly physiological approach to patients with hypothalamic hypogonadism and constitutional delayed puberty (2-4). Stanhope et al. reported that 26 patients with hypothalamic hypogonadism had responded to pulsatile GnRH treatment and attained Tanner stage 3 one year after the treatment (5). However, pulsatile GnRH treatment is not practical for the routine induction of puberty in adolescent children with gonadotropin deficiency since it takes a long time to determine the clinical effectiveness of this treatment.

In our patient, whereas short-term admin- 
istration of GnRH could not produce any pubertal changes, secondary sexual characteristics promptly appeared on treatment with testosterone. These findings suggest that $\mathrm{T}$ administration is more useful than pulsatile GnRH administration in the initial treatment of a patient with constitutional delayed puberty, which it is difficult to differentiate from hypothalamic hypogonadism. Moreover, it may be suggested that the treatment of adolescent children with testosterone or estrogen promotes, more easily and rapidly than $\mathrm{GnRH}$, the pubertal development of the hypothalamo-pituitary-testicular axis by positive feedback.

\section{References}

1. Zachmann M. Therapeutic indications for delayed puberty and hypogonadism in adolescent boys. Horm Res 1991; 36: 141-6.

2. Marshall JC, Kelch RP. Low dose pulsatile gonadotropinreleasing hormone in anorexia nervosa: a model of human pubertal development. J Clin Endocrinol Metab 1979; 49: 712-8.

3. Santoro N, Filicori M, Crowley WF. Hypogonadotropic disorders in men and women: diagnosis and therapy with pulsatile gonadotropinreleasing hormone. Endocr Rev 1986; 7: 11-23.

4. Giusti M, Valenti S, Giordano G. Therapeutic strategies in a male with delayed puberty. Recenti Progressi in Medicina 1992; 83 (11): 634-8.

5. Stanhope R, Pringle P, Brook C. The mechanism of the adolescent growth spurt induced by low pulsatile GnRH treatment. Clinical Endocrinology 1988; 28: 83-91. 